Geografia e Ordenamento do Território, Revista Electrónica

Centro de Estudos de Geografia e Ordenamento do Território

http://cegot.org

ISSN :2182-1267

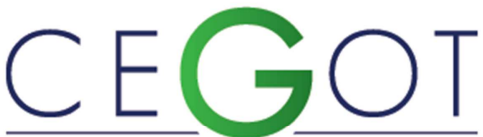

Centro de Estudos de Geografia e Ordenamento do Território
Costa, GEAN

Laboratório de Geografia e Planejamento Ambiental - LABOGEOPA

Universidade Federal de Rondônia (UNIR), 76.8020-80, Porto

Velho, Brasil

gean72@gmail.com

SILVA, GIRLANY

Laboratório de Geografia e Planejamento Ambiental

- LABOGEOPA

Universidade Federal de Rondônia (UNIR), 76.8020-80, Porto

Velho, Brasil

girlanyvaleria@gmail.com

BRAMBILLA, CARLA

Laboratório de Geografia e Planejamento Ambiental - LABOGEOPA

Universidade Federal de Rondônia (UNIR), 76.8020-80, Porto

Velho, Brasil

cdbunir@gmail.com

LOBATO, LUIZ

Instituto Brasileiro de Geografia e Estatística (IBGE)

78.808-462, Porto Velho, Brasil

luiz.lobato@ibge.gov.br

CUNHA, LÚCIO

Faculdade de Letras da Universidade de Coimbra /

Departamento de Geografia / CEGOT

3004-530, Coimbra, Portugal

luciogeo@ci.uc.pt

TELES, VÍRGINA

Universidade do Minho / Departamento de Geografia / CEGOT

4800-058, Guimarães, Portugal

vteles@ics.uminho.pt

NUNES, DORISVALDER

Universidade Federal de Rondônia (UNIR)

76.822-150, Porto Velho, Brasil

dorisval@unir.br

CAvalcante, Maria

Universidade Federal de Rondônia (UNIR)

78.808-462, Porto Velho, Brasil

mada.geoplan@gmail.com

\title{
Ocupações ilegais em unidades de conservação na Amazônia: o caso da Floresta Nacional do Bom Futuro no Estado de Rondônia/Brasil
}

Illegal occupations in environmental conservation areas in the amazon: the Bom Futuro National Forest case in Rondonia state-Brazil 
Referência: Costa, Gean et al. (2015). Ocupações ilegais em unidades de conservação na Amazônia: o caso da Floresta Nacional do Bom Futuro no Estado de Rondônia/Brasil. Revista de Geografia e Ordenamento do Território (GOT), n.o 8 (dezembro). Centro de Estudos de Geografia e Ordenamento do Território, p. 33-49, dx.doi.org/10.17127/got/2015.8.003

\section{RESUMO}

O objetivo deste trabalho é identificar as flexibilidades institucionais a partir da incoerência entre o uso planejado e o uso efetivo na unidade de conservação (UC) da Floresta Nacional (FLONA) do Bom Futuro, localizada no município de Porto Velho, Rondônia, Amazônia, Brasil. A metodologia adotada consistiu no levantamento dos instrumentos normativos (Leis e Decretos) que regem a UC, bem como aquisição de imagens de satélite Landsat-05 e Landsat-08 dos anos 1988, 1997, 2006 e 2014. A flexibilidade institucional identificada na FLONA do Bom Futuro foi motivada por fatores relacionados com as ocupações irregulares, desmatamento e redução dos limites como resultado do problema de antropização, demonstrando ausência de gestão e comprometimento da área a partir dos novos usos impostos.

Palavras-chave: Amazônia. Unidades de Conservação. Uso Normativo. Flexibilidade. Bom Futuro

\section{ABSTRACT}

The objective of this study is to identify the institutional flexibility from the incoherence between the plan used and the effective uses in the protected area (UC) National Forest (FLONA) of Bom Futuro, in Porto Velho, Rondonia, Amazon, Brazil. The methodology was based on the survey of regulatory instruments (Laws and Ordinances) that rules the UC and acquires images from Landsat-05 and Landsat-08 of years 1988, 1997, 2006 and 2014. The institutional flexibility identified in the FLONA of Bom Futuro was motivated by factors related to illegal occupation, deforestation and reduction of limits as anthropization problem result, demonstrating the absence of management and the area commitment from the use of new taxes.

Keywords: Amazon. Protected Areas. Normative use. Flexibilities. Bom Futuro

\section{Introdução}

O Brasil atualmente desempenha papel significativo no âmbito das ações de preservação e conservação dos recursos naturais, principalmente quando se considera a relevância dos biomas brasileiros no contexto mundial. É no final dos anos 30 do século XX que o país institui sua primeira Unidade de Conservação (UC): o Parque Nacional de Itatiaia, mas só a partir de 1972, passou a adotar uma política ambiental institucionalizada, com a criação da Secretaria Especial de Meio Ambiente (SEMA). Em 1981, é instituída a Política Nacional de 
Meio Ambiente com a promulgação da Lei no 6938, o que vai reforçar os investimentos estatais na implantação de áreas protegidas, sobretudo, no âmbito da Amazônia Brasileira (NUNES, 1996). A institucionalização das UC's tem sido o principal mecanismo para manutenção, conservação e/ou preservação da biodiversidade, com especial destaque para região amazônica (ARAÚJO \& BARRETO, 2010; RIBEIRO \& VERISSÍMO, 2007; GTA, 2008).

Grande parte das UC's criadas ou implantadas na Amazônia tem sido pressionada por diversas formas de uso e ocupação, geralmente praticados pelos atores sociais ligados aos setores da pecuária, da soja e da madeira. Somam-se, neste cenário, os pequenos agricultores que, em conjunto com os demais atores, reproduzem um modelo de uso e ocupação que, para além de arcaico é intensivo e irregular, já que avança indiscriminadamente para dentro das áreas diplomadas.

Estas ações estão relacionadas com fatores que vão desde a necessidade social da terra, ao problema da grilagem e da extração ilegal dos recursos naturais. O principal fator para estas incursões está relacionado com a grande quantidade de estradas oficiais e clandestinas dentro dos limites das UC's e no seu entorno. Facilitam ações de uso, ocupações e atividades de desmatamento, denunciando a falta de controle do poder público, o que tem gerado alguma fragilidade na institucionalização de áreas destinadas à conservação a médio e longo prazo. O resultado é a diminuição de seus territórios e até mesmo sua descaracterização completa (FEARNSIDE, 2005 e 2006; GTA, 2008). Ao fazer avaliação do processo de ocupação humana em Rondônia, a partir da colonização agrícola durante os anos 80 do século XX, Fearnside (1989) já apontava o desmatamento como um dos principais indicadores da fragilidade de gestão institucional nas UC's.

Segundo Ribeiro e Veríssimo (2007), há duas principais causas para o aumento do desmatamento nas UC's do Estado de Rondônia: a ausência de ação por parte do poder público para efetivação de proteção dessas áreas e a proximidade dessas UC's dos polos madeireiros e áreas de consolidação da pecuária. O ciclo inicia-se pela extração da madeira e posterior desmatamento, seguido do plantio de pastagem ou cultivo da soja. Este tipo de investimento é responsável pelo chamado efeito de arrasto, aqui definido como " $a$ estimulação de investimento privado como resultado de uma despesa pública em um projeto" (FEARNSIDE, 2000, pg. 76). 
Nos dias atuais, potencializando este efeito de arrasto têm-se em Rondônia, dois grandes empreendimentos em fase de consolidação. Falamos das usinas hidrelétricas de Jirau e Santo Antônio, ambas localizadas no município de Porto Velho, no alto curso do Rio Madeira. As usinas, somadas à expansão da soja e da pecuária, estimulam a pressão antrópica sobre as UC's situadas na área de sua abrangência, com destaque para Floresta Nacional do Bom Futuro-RO. Os problemas ambientais daí decorrentes resultaram na anulação de decretos, na redefiniçao de limites de UC's para acomodação do reservatório das usinas e, claro, na expansão do desmatamento (CAVALCANTE, 2012).

Em quase todas as unidades de conservação situadas na região do alto Rio Madeira o cenário problemático é similar. Para uma análise mais detalhada tomou-se o caso da Floresta Nacional do Bom Futuro, como exemplo negativo de flexibilidade institucional, como resultado da ineficácia da aplicação da legislação e da precária gestão do poder público.

\subsection{Objetivos e Localização da Área de Estudo}

O objetivo principal deste trabalho é identificar as flexibilidades institucionais, aqui entendidas como a incapacidade de gestão das UC's, a partir da incoerência entre o uso planejado e uso o efetivo na Floresta Nacional do Bom Futuro. Esta UC está localizada na Amazônia, município de Porto Velho, Estado de Rondônia, Brasil (Cf. Fig. 01). A série histórica analisada situa-se entre 1988 (ano de sua criação) a 2014, período em que as dinâmicas de uso e ocupação do território em Rondônia se intensificaram, refletindo as atuais taxas de desmatamento e alteração dos limites da UC.

A unidade de conservação Floresta Nacional do Bom Futuro foi implantada ainda na década de 80, no âmbito do Programa de Desenvolvimento da Região Noroeste do Brasil (POLONOROESTE). Logo depois, este programa deu origem ao Plano Agropecuário e Florestal de Rondônia (PLANAFLORO), o qual teve, entre outras funções, a implementação de UC's no Estado de Rondônia e a definição da primeira aproximação do Zoneamento Socioeconômico e Ecológico (ZSEE-RO), instituído em 14 de junho de 1988, pelo decreto estadual $n^{\circ}$ 3.782. Tinha como objetivo minimizar o efeito da ocupação intensiva, estimulada pela abertura de rodovias e pelos projetos de colonização no Estado da década 
de 70, que culminaram na substituição da cobertura vegetal original (PEDLOWSKI, et al., 1999).

A segunda aproximação do ZSEE, homologada pela Lei Complementar $n^{\circ}$ 233/2000, constituiu-se como principal plano de Ordenamento Territorial da política de conservação e preservação do estado de Rondônia (Cf. Fig. 01). Racionalizou o uso do territorio em três grandes Zonas e nove Sub-zonas: Zona 1 (sub-zonas 1.1, 1.2, 1.3 e 1.4) destinada ao uso socioeconômico intensivo. Na sub-zona 1.1 - encontram-se as áreas de grande potencial social, dotadas de infraestrutura para o desenvolvimento das atividades agropecuárias. Nesta verifica-se as maiores densidades populacionais do estado. A sub-zona 1.2 apresenta cobertura florestal natural, porém em processo acelerado de ocupação e desmatamento. A sub-zona 1.3 de expressivo potencial florestal, possui ocupação humana incipiente. Embora indicada como restrita ao desenvolvimento econômico, a sub-zona 1.4 apresenta potencial para preservação dos recursos hídricos.

No que se refere a Zona 2 (sub-zonas 2.1 e 2.2), embora as atividades produtivas sejam permitidas, sua expansão não deve ser estimulada. Para as áreas definidas como sub-zona 2.1, o capital natural (florestal), possui condições para o manejo e conservação de seus recursos naturais. Em sentido mais restrito, a sub-zona 2.2 caracterizou-se pela ocupação inexpressiva, facilitando a conservação ambiental. A Zona 3 (sub-zonas 3.1, 3.2 e 3.3) definiu-se pelas áreas legalmente protegidas (UC's e Terras Indígenas) e como centro da estratégia de conservação em Rondônia (RONDÔNIA, 2001). Na sub-zona 3.1 tem-se as UC's de Uso Sustentável, e a sub-zona 3.2 comporta as UC's atualmente definidas como de Proteção Integral. Por fim, a sub-zona 3.3 refere-se às Terras Indígenas do estado. 


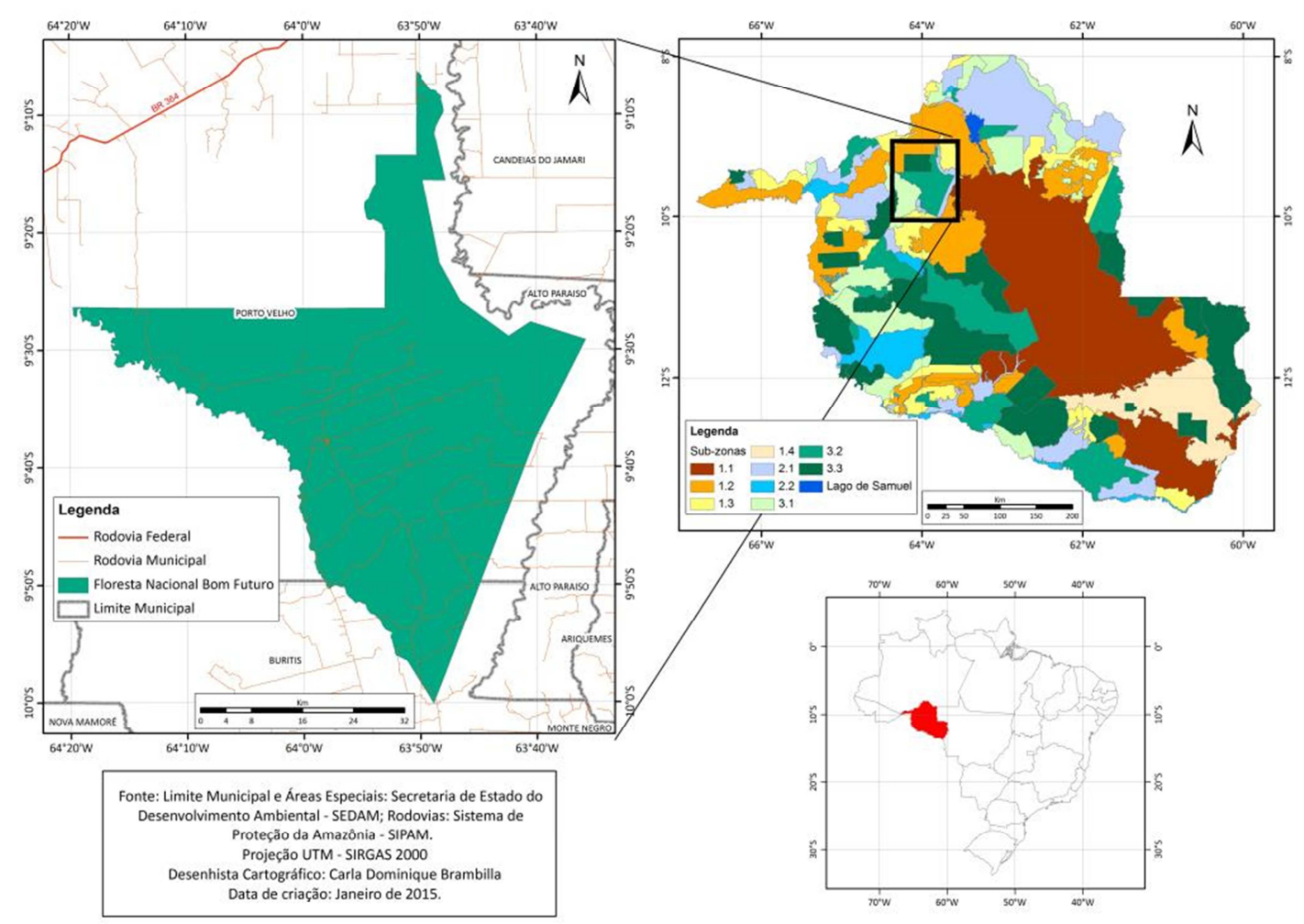

Figura 01 - Mapa de Localização e área original da Floresta Nacional do Bom Futuro e as Sub-zonas de orientação de uso para o ordenamento territorial em Rondônia.

Fonte: Adaptado de Rondônia (2001).

\section{Unidades de conservação e ordenamento do território: contradições entre o uso normativo e o uso efetivo}

A orientação teórico-metodológica deste estudo está pautada na análise das contradições entre o uso normativo e o uso efetivo do território. A ideia é confrontar a orientação dada pela legislação no ordenamento dos territórios voltados para a conservação ambiental, com os processos efetivos de usos e ocupações, os quais incidem no aumento do desmatamento em unidades de conservação, indicando um sério comprometimento na proteção destas áreas.

As UC's destinam-se a formas específicas de uso, chanceladas pela Lei no 9985/2000. No entanto, é possível evidenciar que, no caso da FLONA do Bom Futuro, a ausência de gestão favoreceu a ocupação irregular de parte de sua área. Esta levou a uma revisão legislativa, de 
modo a atender a objetivos diferentes daqueles indicados na Lei inicial. Por isso, o conceito de território ganha importância neste contexto, quando passa a ser entendido não pelos limites de área, mas pelos usos que dada sociedade imprime sobre esta mesma área, lastreada pelo exercício de poder dos diferentes grupos de interesse (RAFFESTIN, 1993; SAQUET, 2010; CAVALCANTE, 2012; RODRIGUES et al., 2013).

O território é analisado sob a perspectiva do uso normativo, portanto, como resultado da regulamentação definida no âmbito do aparelho estatal e gerido pelos diversos agentes nele existentes, representados pelo Poder Público e pelas instituições civis e empresariais que, através de meios jurídicos (decretos ou acordos), compromissos, valores, ou mesmo costumes, materializam as suas ações por meio da coerção normativa, cujo intuito é o controle e um novo ordenamento do território (SAQUET, 2011; CAVALCANTE, 2008).

Toma-se como objeto de análise do uso normativo do território o Sistema Nacional de Unidades de Conservação - SNUC (Lei n 9.985/2000), e o Sistema Estadual de Unidades de Conservação do Estado de Rondônia - SEUC/RO (Decreto lei $\left.n^{\circ} 1.144 / 2002\right)^{1}$, a partir dos quais se chega à noção de Unidades de Conservação, que define essas áreas como o "Espaço territorial e seus recursos ambientais, [...] legalmente instituídos pelo Poder Público, com objetivos de conservação e limites definidos, ao qual se aplicam garantias adequadas de proteção" (BRASIL, 2000, pg. 13). São de dois tipos ou grupos: as UC's de Uso Sustentável, as quais têm por objetivo compatibilizar a conservação da natureza com o uso econômico, a partir da noção de sustentabilidade de parte dos seus recursos naturais; as UC's de Proteção Integral, que têm como objetivo preservar a natureza, sendo admitido apenas o uso indireto dos seus recursos naturais, com exceção dos casos previstos em Lei, a exemplo das atividades de pesquisa científica (BRASIL, 2000). A FLONA Bom Futuro está categorizada como de Uso Sustentável e, ao contrário das categorias de Proteção Integral apresenta, por força da Norma, um grau de fragilidade maior.

\subsection{O Uso normativo do Território nas UC's de Rondônia}

Embora as UC's compreendam territórios especiais independentemente de sua categoria, Heidrich (2010) afirma que nem sempre o que é legislado é o que vigora efetivamente no

\footnotetext{
${ }^{1}$ Rondônia (2002).
} 
uso destes territórios, caracterizado no âmbito do SNUC. Os dados tendem a apresentar uma situação inversa, como apresentado em Soares Filho et al. (2006) e em Ribeiro \& Veríssimo (2007) ao discorrerem sobre as trajetórias atuais e os cenários possíveis para a conservação da floresta amazônica. Atualmente existem três posições diante do contexto Amazônico: 1) a dos que desejam intensificar o uso e exploração dos recursos naturais da região sem nenhuma preocupação ambiental; 2) os que desejam promover a exploração, obedecendo a critérios conservacionistas; e 3) os que radicalizam as pretensões de preservar a Amazônia como santuário ambiental de forma intocada pelo Ser Humano (ANDRADE, 2004).

No caso do Estado de Rondônia prevalece a primeira posição que se materializa no processo de exploração dos recursos naturais sem nenhuma preocupação ambiental. Isso se testemunha através dos levantamentos realizados para este estudo que dão conta de que, historicamente, a FLONA Bom Futuro tem sido submetida a recorrente pressão antrópica para uso de seus recursos naturais.

O processo de desmatamento acelerado na Amazônia é iniciado, normalmente, com a abertura oficial ou clandestina de estradas que permitem a instalação de ocupações irregulares e, particularmente, a expansão do uso da terra, sobretudo, no entorno das unidades de conservação. Com os processos intensificados converte-se a floresta em terras de cultivo agrícola e em pastagens para criação de gado, sendo este processo responsável por cerca de $80 \%$ das florestas desmatadas na Amazônia Legal (FERREIRA et al., 2005; FERNSIDE, 2006 e 2005).

As unidades de conservação na Amazônia vêm sediando parte desta dinâmica territorial, onde se constata que as ocupações irregulares determinam as flexibilidades legislativas impostas pelo Poder Público, não como alternativa de solução, mas como resultado da ausência ou ineficácia de gestão, tornando-as vulneráveis às alterações, a partir das intenções de uso e a consequente alteração da cobertura vegetal original. Estes usos são potencializados com investimentos estatais e privados de grandes infraestruturas hidrelétricas, pavimentação de estradas e o agronegócio (NUNES, 2004; MARTINS et al., 2014). 
Estudos realizados pelo Grupo de Trabalho Amazônico - GTA (2008), afirmaram que a invasão da FLONA do Bom Futuro se deu a partir do ano de 2000. Inicialmente o processo ocorreu pela ação ilegal de grileiros e especuladores de terras por meio da retirada ilegal da madeira e, em seguida, pela ausência de gestão, conivência política e anuência dos próprios políticos locais, os quais foram omissos, permitindo que a ocupação tomasse uma proporção expressiva, causando o desmatamento, o que mais tarde contribuiu para a desafetação legal de uma parte significativa do território da unidade.

\section{Materiais e métodos}

Os procedimentos metodológicos adotados para este estudo consistiram em: a) levantamento dos instrumentos normativos (Leis e Decretos) que regem a UC Bom Futuro; b) aquisição de imagens de satélite do Landsat-05 Bandas 4R, 3G, 2B, das órbitas-ponto: 232-66 e 232-67, dos anos 1988, 1997 e 2006, disponíveis no banco de imagens de satélite do Instituto Nacional de Pesquisas Espaciais - INPE, bem como o banco de imagens do Satélite Landsat-08, bandas 6R, $5 \mathrm{G}$ e 4B, das órbitas-ponto: 232-66 e 232-67 para o ano 2014, fornecidas pela NASA. Utilizou-se ainda a imagem Geocover do ano 2014 para o georreferenciamento das imagens acima mencionadas. Assim, conseguiu-se uma série histórica de 16 anos, conforme organograma da Figura 02.

Após a construção dos mosaicos das imagens para os anos 1988, 1997, 2006 e 2014 foi realizada a classificação supervisionada através do Software ARCGIS 9.3 utilizando a imagem de satélite georreferenciada e suas respectivas classes de acordo com áreas desmatadas. Por meio da ferramenta Spatial Analyst Tools >Multivariate > Maximum Likehood Classification definiram-se as classes de uso. No pós-processamento foram estabelecidos filtros para correção e dispersão de pixels isolados, obtendo assim melhores resultados e a construção do mapa temático da Figura 04. 


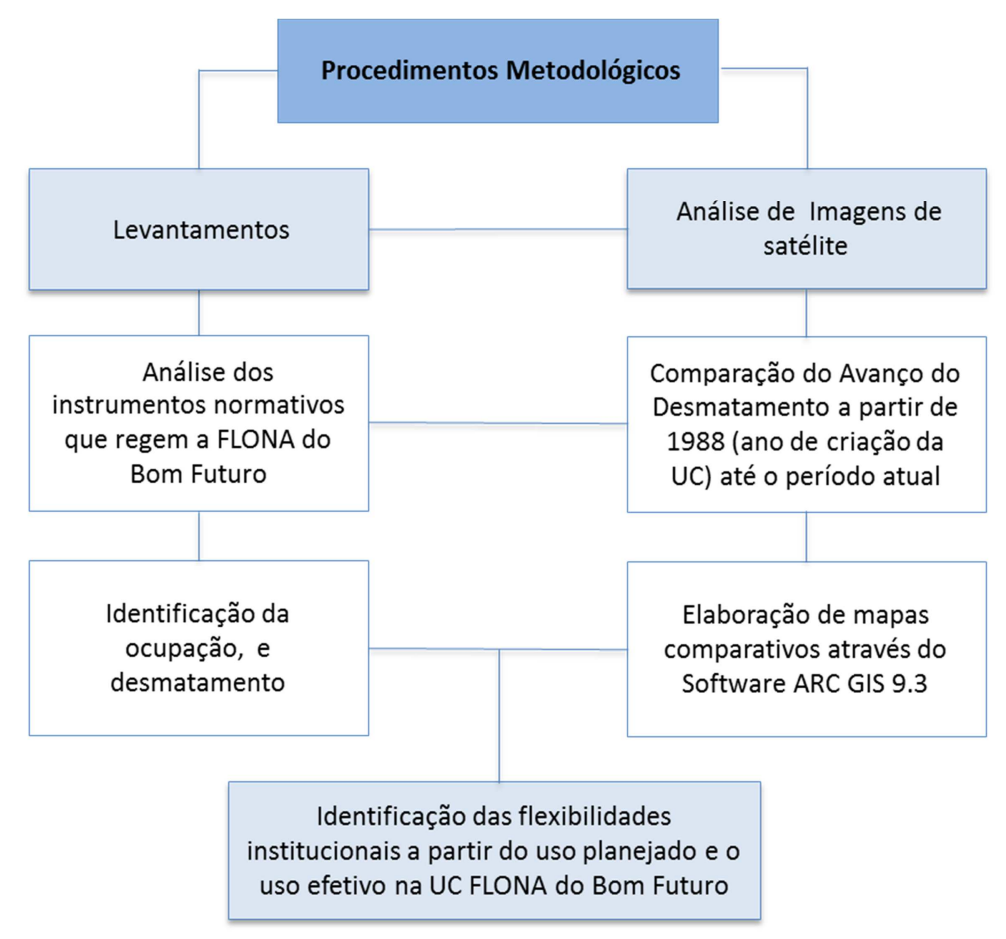

Figura 02 - Organograma metodológico.

De posse dos instrumentos normativos que regem a UC e dos dados históricos sobre os desmatamentos foi possível a sua comparação, permitindo a identificação entre o uso planejado e uso efetivo predominante.

\section{Resultados e discussões}

A FLONA do Bom Futuro foi inicialmente implantada no contexto do Programa de Desenvolvimento da Região do Noroeste do Brasil (POLONOROESTE), com uma área de aproximadamente 280.000 hectares. Está localizada nos municípios de Buritis e Porto Velho, Estado de Rondônia, Brasil. Classificada como UC de Uso Sustentável, foi regulamentada pelo decreto-lei $n^{\circ}$ 96.188, de 21 de Junho de 1988. 
Embora as pressões de ocupações irregulares em unidades de conservação na região Amazônica se tenham tornado recorrentes, no caso da FLONA do Bom Futuro, essa dinâmica é relativamente recente, e está associada à formação do povoado de Rio Pardo, no interior da unidade. As dinâmicas territoriais impostas pelas grandes infraestruturas (hidrelétricas) e pela expansão do agronegócio (soja e pecuária) reforçam a pressão sobre a área. A falta de gestão na FLONA Bom Futuro foi potencializada pela flexibilização institucional no trato da gestão, que culminou no processo de ocupação irregular e posterior redução de seus limites.

O principal resultado foi expresso no avanço do desmatamento que, para o ano de 2006, alcançou a marca de cerca de 42.926 hectares o que representou um percentual de 15,33\% dos 280.000 hectares de sua área original. Em 2014 o desmatamento dobraria para 87.630 hectares, caso não tivesse acontecido a desafetação de parte da área da UC, mascarando a realidade do desmatamento dentro de seus limites (Cf. Fig. 3).

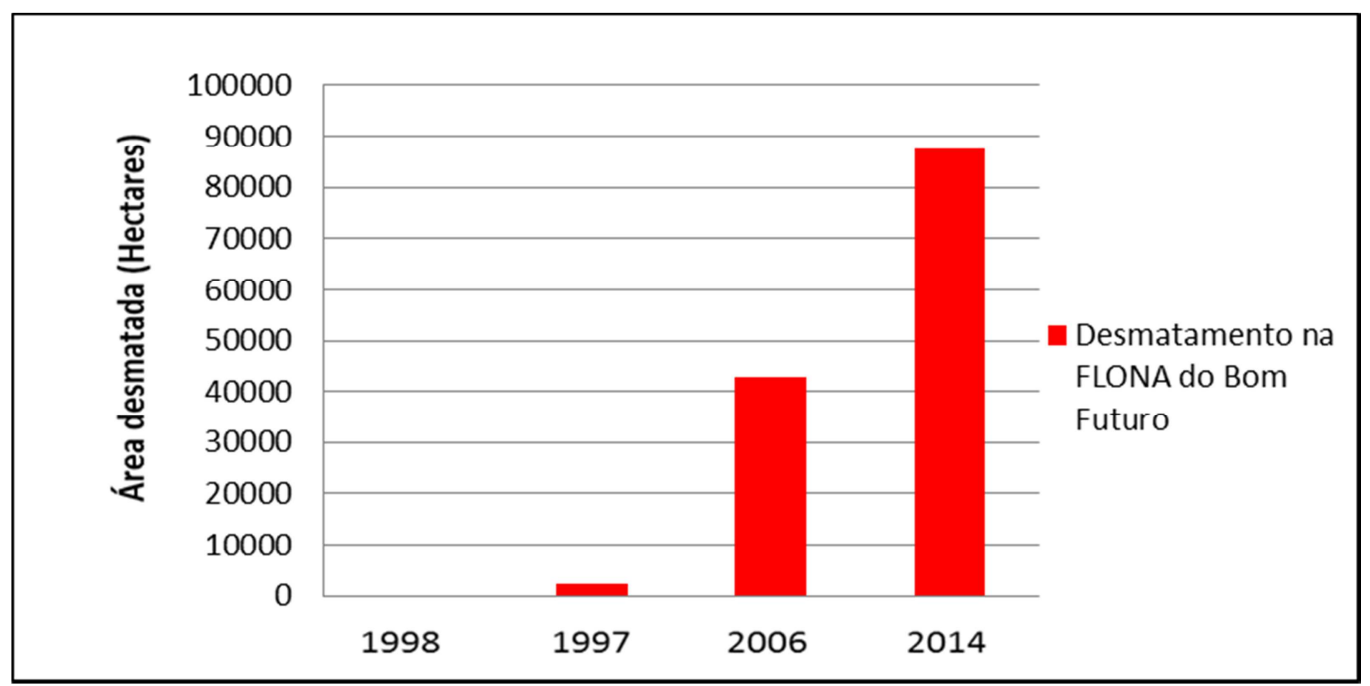

Figura 03 - Área desmatada na Floresta Nacional do Bom Futuro entre 1988 a 2014.

Fonte: Organizado a partir de dados Instituto Nacional de Pesquisas Espaciais - INPE (INPE, 2015).

De acordo com Cavalcante et al. (2011), a FLONA do Bom Futuro ficou em segundo lugar entre as unidades mais desmatadas da Amazônia Legal, no período que vai de agosto de 2007 a abril de 2008. O desmatamento inicialmente se deu pela ocupação ilegal, com extração irregular de madeiras, realizada por empresas madeireiras dos municípios do entorno da área. É interessante observar os dados levantados por VERÍSSIMO et al. (2011) 
que ao analisarem a série histórica que vai de 1997 a 2009, demonstraram que em todos os anos da referida série, o destaque no desmatamento acumulado nas áreas protegidas se deu nas unidades categorizadas como de Uso Sustentável. A partir dos dados observou-se concentração dos altos índices de desmatamento nessa categoria, não importando ser da alçada estadual ou federal. Nas duas instâncias governamentais o desmatamento é recorrente para a categoria de UC's de uso sustentável.

A invasão generalizada por pequenos agricultores, pecuaristas, garimpeiros e, principalmente, pelos madeireiros é o resultado não apenas das flexibilidades institucionais, mas a própria condição de fragilidade que enseja as Unidades de Conservação de Categoria Uso Sustentável, seja no caso amazônico ou em Rondônia (RIBEIRO \& VERISSíMO, 2007).

No ano de 2010, a FLONA do Bom Futuro, que estava sob gestão do governo Federal, teve parte de sua área cedida ao Estado de Rondônia, revelando o interesse do governo Estadual em caucionar a ocupação por cerca de 5.000 habitantes que haviam invadido a área protegida, conforme indicado na Figura 04 (CAVALCANTE, 2012).

O que se depreende do mosaico, é que o procedimento adotado aconteceu mais pela conveniência do Poder Público, do que efetivamente pelo observar do que dispõe a legislação. A flexibilização aqui teve apenas por objetivo legalizar o que dantes poderia ser caracterizado como ilegal. Obviamente este procedimento contribuiu para a efetivação do povoado de Rio Pardo, obrigando neste caso reduzir o tamanho da área original da FLONA do Bom Futuro (Fig. 4, cena de 2014), perfazendo atualmente uma área de 97.357 hectares, conforme homologação dada pela lei complementar $n^{\circ} 12.249$, de $11 / 07 / 2010$. O critério adotado passou ao largo dos estudos de potencialidades ecológicas ou cênicas da área. 


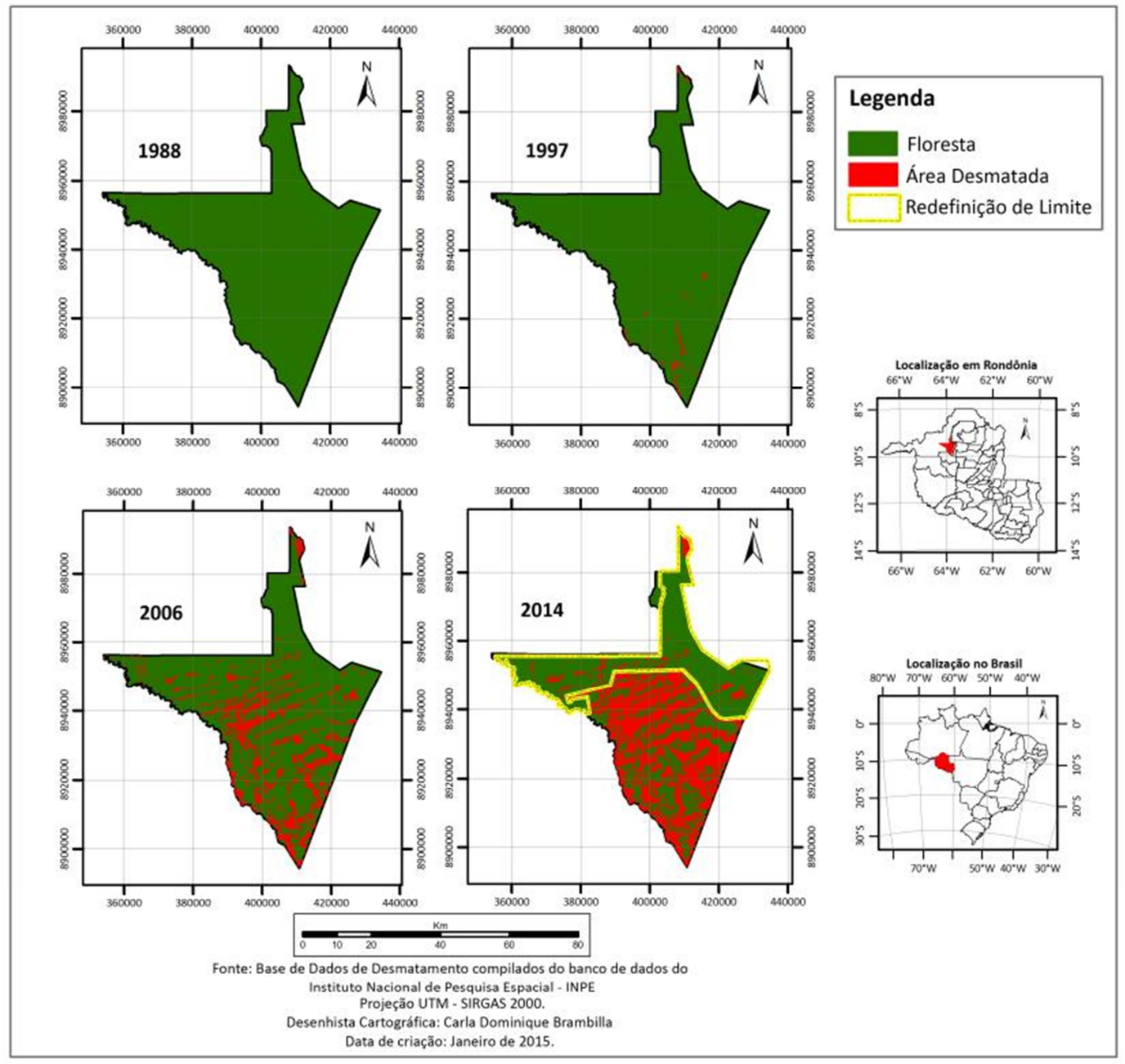

Figura 04 - Área de desmatamento da Floresta Nacional do Bom Futuro entre os anos de 1988 a 2014.

Fonte: INPE (2015).

Para além das conveniências políticas do Poder Público de Rondônia na redução da reserva, foi observado também que o Governo Federal manifestou interesse na proposta de redução da área, pois terminou permutando com outras unidades de conservação localizadas no estado de Rondônia, as quais se situavam estrategicamente no entorno das usinas hidrelétricas do Alto Rio Madeira, sobretudo, da usina de Jirau. A ampliação de áreas legalmente protegidas poderia ser vista como alternativa à conservação frente aos impactos das usinas que poderia ser considerado um reforço à causa do empreendimento e, por conseguinte, "uma ação politica e ecologicamente correta" (ARAÚJO \& BARRETO, 2010; CAVALCANTE, 2012; 2014). 
Neste cenário, a FLONA do Bom Futuro passou a ter nova configuração, onde, no ano de 2010, foram criadas 2 (duas) unidades de conservação na área desafetada (144.417 hectares-área reduzida): Área de Proteção Ambiental de Rio Pardo e Floresta Estadual Sustentável de Rio Pardo. Estas alterações foram efetivadas pela lei complementar $n^{\circ} 581$, de 30/07/2010 (MARTINS et al., 2014). Portanto, é possível observar vários interesses sobrepostos em Unidades na Amazônia, mais especificamente, na FLONA do Bom Futuro. A redefinição de limites encontrada nesta UC é o reflexo dos vários processos de usos e ocupações, seguidos dos desmatamentos que ocorrem na região com maior ou menor frequência, mas sempre crescentes.

As alterações realizadas encontram-se em desacordo com o Decreto Lei 1.144/2002 do Sistema Estadual de Unidades de Conservação - SEUC-RO, que no Art. 21, § 6ㅇ, quando trata da desafetação ou redução dos limites de uma unidade de conservação, afirma que só pode haver alteração em áreas legalmente protegidas, mediante lei específica e, obrigatoriamente, precedida de estudos técnicos que justifiquem o ato. No entanto, verificou-se que no caso da FLONA do Bom Futuro, a alteração foi realizada pelo poder público inobservando o que dispõe a legislação, ou seja, sem estudos técnicos para a desafetação e outras alterações ocorridas.

A flexibilização institucional que, por um lado não observa a norma e, por outro, tenta legitimar suas ações, tende a comprometer a gestão da área o que permitiu para o caso aqui abordado: 1) a instalação da população no interior da FLONA; 2) ao governo do Estado ter o domínio de parte dessa área, em função da troca de outras duas UC's com o governo federal; 3) redução dos limites da FLONA do Bom Futuro; e 4) o precedente jurídico que o histórico da FLONA Bom Futuro abre para outras incursões de diminuição de UC's na Amazônia, quando submetidas a pressões antrópicas. Por fim, há incoerência entre o uso planejado e o uso efetivo da Flona Bom Futuro. Este modelo poderá repetir-se para outras unidades de conservação situadas em Rondônia, concorrendo para o enfraquecimento da política de conservação ambiental do estado e, por que não dizer, da Amazônia. 


\section{Considerações finais}

Embora se possa considerar legítima a luta de colonos (pequenos agricultores familiares) expropriados pela aquisição da terra, as pressões derivadas das ocupações irregulares em unidades de conservação na região Amazônica são marcadas por uma série de interesses. No caso evidenciado, o poder econômico e, sobretudo, o político utilizaram-se da flexibilidade institucional para possibilitar a redefinição dos limites da FLONA do Bom Futuro, por meio legislativo, de modo a atender alguns interesses que são contrários à conservação dos recursos naturais, nomeadamente homologando ocupações irregulares.

Neste contexto, o processo de ocupação irregular que deu origem ao povoado denominado Rio Pardo resultou na desafetação (redução) de uma parte da UC, o que evidencia a atuação tardia da gestão, caracterizando a flexibilidade institucional quanto ao poder de decisão, por conveniência política e ausência de um plano de gestão ambiental, em que o planejamento efetivo é determinado pelas pressões impostas, ampliando a tensão sobre a unidade de conservação, comprometendo-a e acenando novas possibilidades de usos que divergem da conservação e dos instrumentos de Ordenamento Territorial.

\section{Referências bibliográficas}

ANDRADE, Manuel Correia. A questão do território no Brasil. 20 edição. São Paulo: Hucitec. 2004. ISBN 85-2710318-4.

ARAÚJO, Elis; BARRETO, Paulo. Ameaças formais contra as Áreas Protegidas na Amazônia. O Estado da Amazônia. N 16. IMAZON. 2010. Disponível em: <http://goo.gl/SQOtmj>. Acesso em 21 jul. 2014.

BRASIL. Decreto-lei no 9.985 Lei $n^{\circ}$ 9.985, de 18 de julho de 2000. Sistema Nacional de Unidades de Conservação da Natureza - SNUC. Disponível em:<http://goo.gl/IOI3CG>. Acesso em 21 jul. 2014.

CAVALCANTE, Maria Madalena de Aguiar. Transformações Territoriais no Alto rio Madeira: Hidrelétricas, Tecnificação e (re)organização. Dissertação (Mestrado em Geografia) - Universidade Federal de Rondônia UNIR. Programa de Pós-Graduação em Geografia - PPGG. Porto Velho - RO. 2008.

CAVALCANTE, Maria Madalena de Aguiar; NUNES, Dorivalder Dias; LOBATO, Luiz Cleyton Holanda Lobato; SOUZA, Samara Sena; ROCHA, Mario Eugenio; NASCIMENTO, Bárbara Karina Barbosa do. Pressão sobre Áreas destinadas às Unidades de Conservação em Rondônia. In: Il Congresso Brasileiro de Gestão Ambiental. IBEAS Instituto Brasileiro de Estudos Ambientais. 2011. Londrina.

CAVALCANTE, Maria Madalena de Aguiar. Hidrelétricas do Rio Madeira-RO: território, tecnificação e meio ambiente. Tese (Doutorado em Geografia) - Programa de Pós-Graduação em Geografia da Universidade Federal do Paraná, UFPR. Curitiba - PR. 2012. 
CAVALCANTE, Maria Madalena de Aguiar. Hidrelétricas na Amazônia e impactos ambientais: Avanços e perspectiva na gestão Ambiental. In: CAVALCANTE, Maria Madalena de Aguiar. Gestão ambiental desafios e possibilidades. 10 edição. Curitiba/PR: CRV. 2014. Pág. 35-54.

FEARNSIDE, Philip M. Ocupação Humana de Rondônia: impactos, limites e Planejamento. Brasília, Assessoria Edital e Divulgação Científica, Programa Polonoreste, Relatório de Pesquisa no 5, SCT\PR\CNPq, 1989.

FEARNSIDE, Philip M. O avanço da soja como ameaça à biodiversidade na Amazônia. In: Anais. V Simpósio de Ecossistemas Brasileiros: conservação, Vitória: UFES, 10 a 15 de outubro de 2000.

FEARNSIDE, Philip M. Desmatamento na Amazônia brasileira: história, índices e consequências. Megadiversidade. Volume 1. № 1. 2005. Pág. $114-123$.

FEARNSIDE, Philip M. Desmatamento na Amazônia: dinâmicas e controle. Acta Amazônia. Volume 36 (3). 2006. Pág. $395-400$.

GTA. Grupo de trabalho Amazônico. O fim da Floresta: A devastação das unidades de conservação e terras indígenas no Estado de Rondônia. 2008.

HEIDRICH, Álvaro Luiz. Espaço e multiterritorialidade entre territórios: Reflexões sobre a abordagem territorial. In: PEREIRA, S.R; COSTA. B.P; SOUZA, E.B.C. Teorias e práticas territoriais: análises espaço-temporais. 1a edição. São Paulo: Expressão Popular. 2010. Pág. 14-36.

INPE. Instituto Nacional de Pesquisas Espaciais. Catalogo de Imagens. São Paulo - São José dos Campos. 2015. Disponível em: < http://www.obt.inpe.br>. Acesso em 05 jan.2015.

MARTINS, Heron; ARAÚJO, Elis; VEDOVETO, Mariana; MONTEIRO, Dyeden; BARRETO, Paulo. Desmatamentos em áreas Protegidas reduzidas na Amazônia. 2014. Disponível em: <http://goo.gl/SOulNf>. Acesso em 20 jun. 2014.

NUNES, Dorisvalder Dias. Gestão Ambiental em Rondônia: políticas públicas em unidade de conservação - o caso Cuniã. Dissertação de Mestrado, FFLCH/DG/USP, 1996, São Paulo.

NUNES, Dorisvalder Dias. Hidrovia do Madeira: (Re)configuração, integração e meio ambiente. Tese. p. 379. (doutorado), Universidade Federal do Pará, 2004, Belém.

RAFFESTIN, Claude. Por Uma Geografia do Poder. Trad.: Maria Cecília França, São Paulo: ATICA, 1993. ISBN:

SOARES-FILHO, Britaldo Silveira; NEPSTAD, Daniel Curtis; CURRAN Lisa M; CERQUEIRA, Gustavo Coutinho; GARCIA, Ricardo Alexandrino; RAMOS, Claudia Azevedo; VOLL, Eliane; MACDONALD, Alice McDonald; LEFEBVRE, Paul; SCHLESINGER, Peter. Modelling Conservation in the Amazon Basin. In: Nature, Letters, Vol 440|23 March 2006|doi:10.1038/nature04389.

PEDLOWSKI, Marcos; DALE, Virginia; MATRICARD, Eraldo. A criação de áreas protegidas e os limites da conservação ambiental em Rondônia. Ambiente \& sociedade. Ano II. № 5. 2o semestre de 1999. Pág. 93-107.

FERREIRA, Leandro Valle; VENTICINQUE, Eduardo; ALMEIDA, Samuel. O desmatamento na Amazônia e importância das áreas protegidas. Estudos Avançados 19 (53), 2005. Pág. 157-165.

RIBEIRO, Beatriz; VERÍSSIMO, Adalberto; PEREIRA, Kátia. O Avanço do desmatamento sobre as áreas protegidas em Rondônia. O Estado da Amazônia. № 6. IMAZON. 2005. Disponível em: < www.imazon.org.br>. Acesso em: 20 Jun. 2014

RIBEIRO, Beatriz \& VERÍSSIMO, Adalberto. Padrões e causas do desmatamento nas áreas protegidas de Rondônia. In: FUNDAÇÃO BOTICÁRIO DE PROTEÇÃO A NATUREZA. Natureza e conservação. № 1. Volume 5. Curitiba-PR. SK editora. 2007. Pág. $15-26$.

RODRIGUES, Bruna; NUNES, Dorisvalder Dias; FLORES, Cíntia; CAVALCANTE, Maria Madalena de Aguiar. Hidrelétricas e unidades de conservação: conflitos de interesse sob o uso normativo do território no alto rio Madeira/Rondônia. In: VI - Seminário Brasileiro sobre Áreas Protegidas e Inclusão Social/ I - Encontro Latinoamericano sobre Áreas Protegidas e Inclusão Social. Belo Horizonte/ MG. 2013. Pág. 467 - 477.

RONDÔNIA, Plano Agroflorestal de Rondônia - PLANAFLORO. Porto velho: TECNOSSOLOS, Relatório Técnico, 2001. 
RONDÔNIA. Decreto lei no 1.144, de 12 de Dezembro de 2002. Sistema Estadual de Unidades de Conservação da Natureza de Rondônia - SEUC/RO e dá outras providências. Disponível em: < http://goo.gl/LfOMBm>. Acesso em: 21 jul. 2014.

SAQUET, Marcos Aurélio. Abordagens e concepções de território. 2a edição. São Paulo: Expressão Popular. 2010. ISBN 978-85-7743-040-6

SAQUET, Marcos Aurélio. Por uma geografia das territorialidades e das temporalidades: uma concepção multidimensional voltada para cooperação e para o desenvolvimento territorial. 1a edição. São Paulo: Outras Expressões. 2011. ISBN 978-85-64421-08-0

VERÍSSIMO, Adalberto; ROLLA, Alícia; VEDOVETO, Mariana; FUTADA, Silvia de Melo. Áreas Protegidas na Amazônia Brasileira: avanços e desafios. Belém, IMAZON; São Paulo, ISA, 2011. 